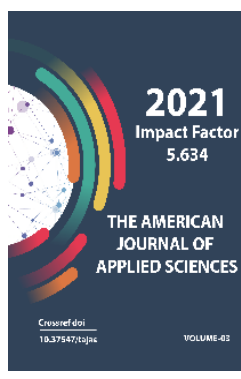

Journal Website: https://theamericanjou rnals.com/index.php/ta jas

Copyright: Original content from this work may be used under the terms of the creative commons attributes 4.0 licence.

\section{Morphological Assessment Of Wounds Healing In The Region Of Anal Canal In Rats On The Background Of Medicamental Hypocoagulation}

\author{
R.Yu. Ruzibayev \\ Urgench Branch Of The Tashkent Medical Academy, Urgench, Uzbekistan \\ P.Yu. Ruzmatov \\ Urgench Branch Of The Tashkent Medical Academy, Urgench, Uzbekistan \\ D.A. Umarov \\ Urgench Branch Of The Tashkent Medical Academy, Urgench, Uzbekistan
}

\title{
ABSTRACT
}

Purpose of the study: to conduct a morphological study of experimental material to assess the features of wound healing in the anal sphincter area when using the domestic drug "Heprocel" as a hemostatic agent.

Material and methods. The study was carried out in the Department of experimental surgery and the department of pathological anatomy of the Republican Specialized Scientific and Practical Medical Center for Surgery named after Academician V. Vakhidov. The state of experimental models of wounds with the application of a hemostatic agent in the form of a gel was studied. The experiments were carried out on 72 white male rats weighing $210-250 \mathrm{~g}$. Two series of 36 animals each were produced. All animals were divided into groups: norm - experiment in the absence of drug hypocoagulation; control - an experiment with intravenous heparin to achieve drug hypocoagulation; experience - an experiment with intravenous administration of heparin to achieve drug hypocoagulation using an application on a model of a skin wound and a dissected anal sphincter of the hemostatic agent "Heprocel".

Results. Morphological differences in the process of wound healing were most pronounced after 3 days of the study. In the control group of animals with hemostasis using an electrocoagulator, necrotic and exudative processes of inflammation in the stratified squamous epithelium and mucous membrane of the glands in the anal region were evident. In the experimental group, on the 3-5th day of the experiment, the proliferative process of inflammation predominated morphologically. A special feature is that the hemostatic gel is absorbed into the wound, forming a thin uniform layer. On the 10th day of the experiment, the above difference became more obvious. In the control group, chaotic squamous epithelial cells and fibroblasts were formed. The fibrin-necrotic layer is preserved. Focal infiltration of macrophages-lymphocytes was observed. In the experimental group, the intestinal layers began to change. In the area of the surgical incision, the hemostatic layer is preserved; in this 
area, the growth of thin fibrous connective tissue is observed. Differentiation and transformation of cells led to the regeneration of the epithelial layer and parakeratosis of the flat cell. Signs of complete remodeling were evident over a long period of time, such as 14 days.

Conclusion. The use of a hemostatic agent in the form of a gel provides not only an increase in the processes of local hemostasis, but a decrease in the activity of inflammatory reactions and infection, as well as the risk of developing post-traumatic cicatricial deformity of the anus.

\section{KEYWORDS}

Experimental study, morphology, model of anus wound, drug hypocoagulation, hemostasis, "Heprocel”.

\section{INTRODUCTION}

Today, hemorrhoids are characterized by their relevance among coloproctological diseases. There is many data on the pathogenesis and course of hemorrhoidal disease, the clinical picture of hemorrhoids, which is diverse in a wide range and requires careful differential diagnosis $[1,2,3]$.

The study of literature data indicates the need to search for new scientifically substantiated forms of surgical treatment of hemorrhoidal disease against the background of concomitant diseases. Some specific clinical conditions, including concomitant cardiovascular pathology, against the background of hypocoagulation therapy and regular rectal bleeding, complicate the treatment of hemorrhoids, cause its progression and worsen outcomes [4].

Despite the many proposed different options for surgical interventions for hemorrhoids, the results of surgical treatment are not always positive $[5,6]$. The existing modified methods prototypes do not provide all the required conditions for the surgical treatment of chronic hemorrhoids III-IV stages against the

background of drug hypocoagulation, and are associated with the development of postoperative complications such as bleeding, narrowing of the anal canal and eruption of sutures after stool with prolonged wound healing, since at all In the above operations, a closed or open wound surface remains in the rectum [7, 8]. In this aspect, the most pressing issues of colorectal surgery are the development of drugs and technologies aimed at enhancing the processes of local hemostasis, reducing the activity of inflammatory reactions and infection, reducing the risk of recurrent bleeding, as well as the risk of developing post-traumatic cicatricle deformity of the anus $[9,10]$.

The aim of the study was to conduct a morphological study of experimental material to assess the features of wound healing in the anal sphincter area when using the domestic drug "Heprocel" as a hemostatic agent. 


\section{MATERIAL AND METHODS}

We have proposed an improved method for the surgical treatment of chronic combined hemorrhoids, including the use of the domestic hemostatic drug "Heprocel". As an evidence base, the results of a morphological study of biomaterials obtained from experimental animals after surgery on days 3, 5, 10 and 14 are presented. The study was carried out in the department of experimental surgery and the department of pathological anatomy of the Republican Specialized Scientific and Practical Medical Center for Surgery named after Academician V. Vakhidov. The state of experimental models of wounds with the application of a hemostatic agent in the form of a gel was studied. The obtained biomaterials were prepared in a standard way: they were fixed in $10 \%$ formalin solution in phosphate buffer. Paraffin sections were stained with hematoxylin and eosin. Light-optical micrographs were obtained using a "Biolam I" microscope coupled to a digital camera and a computer.
The experiments were carried out on 72 white male rats weighing 210-250 g. Two series of 36 animals each were produced. All animals were divided into groups: norm - experiment in the absence of drug hypocoagulation; control - an experiment with intravenous heparin to achieve drug hypocoagulation; experience - an experiment with intravenous administration of heparin to achieve drug hypocoagulation using an application on a model of a skin wound and a dissected anal sphincter of the hemostatic agent "Heprocel". The experiments were carried out in compliance with the requirements of the European convention for the protection of vertebrate animals used for experimental and other scientific purposes (Strasbourg, 1986).

Gel "Heprocel" (Fig. 1) from cellulose derivatives for hemostasis. Physicochemical characteristics of the preparation: translucent gel, homogeneous thick consistency. It dissolves in water and saline. Hygroscopic. $\mathrm{pH}$ 5-7. Active ingredients: sodium carboxymethyl cellulose (medical); viscose; calcium chloride "chemically pure"; distilled water.

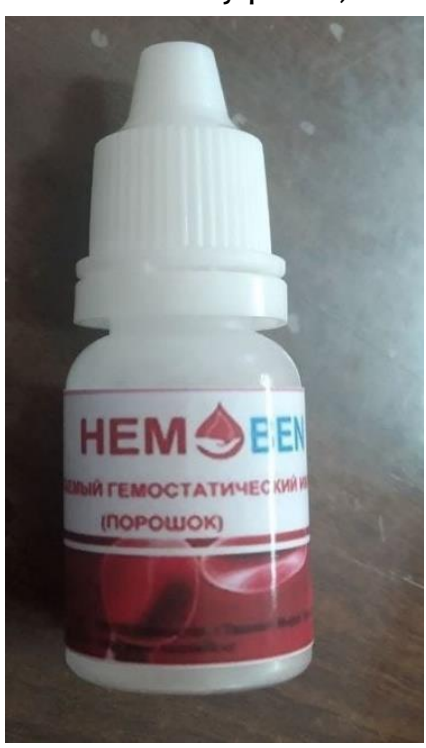

Rice. 1. Domestic hemostatic agent "Heprocel" 
The American Journal of Applied sciences

(ISSN - 2689-0992)

Published: September 24, 2021 | Pages: 5-15

2021: 5.634

Doi: https://doi.org/10.37547/tajas/Volume03Issue09-02

OCLC - 1121105553

Basic physical and chemical characteristics: Hemostatic gel is obtained by dissolving sterile "Heprocel" powder in physiological solution at a concentration of $4 \%$. The resulting thick viscous gel is impregnated with medical sterile gauze immediately before use.

\section{RESULTS}

Morphological differences in the process of wound healing were most pronounced after 3 days of the study. In the control group, necrotic-exudative inflammation processes

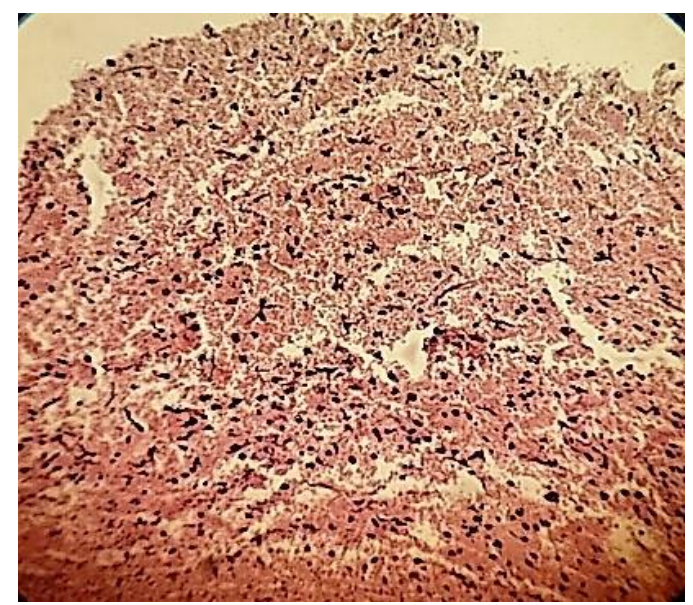

Fig. 2 Control group. $3^{\text {rd. }}$ day. Necroticdestructive zone.

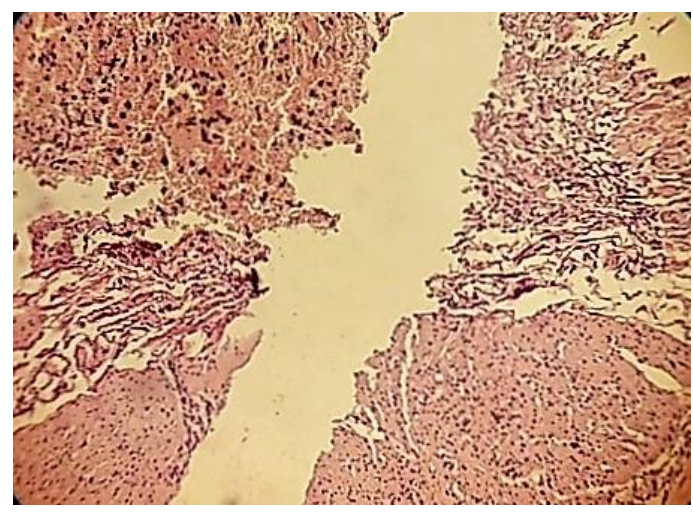

Fig. 4. Control group. $3^{\text {rd. }}$ day. Cell-free zones areas of edema, extravascular erythrocytes and focal infiltration of macrophages. were evident, since they cause deep tissue necrosis due to high electrical energy (hemostasis with the help of an electrocoagulator) (Figs. 2 and 3). These include necrotic changes in the stratified squamous epithelium and mucous membrane of the glands in the anal region, focal infiltration of lymphocytes-macrophages in the submucosal layer, chaotic changes in the layer of connective tissue, thickening of the vessel wall, dilatation and stagnation. Swelling is observed throughout the entire layer (Figs. 4 and 5).

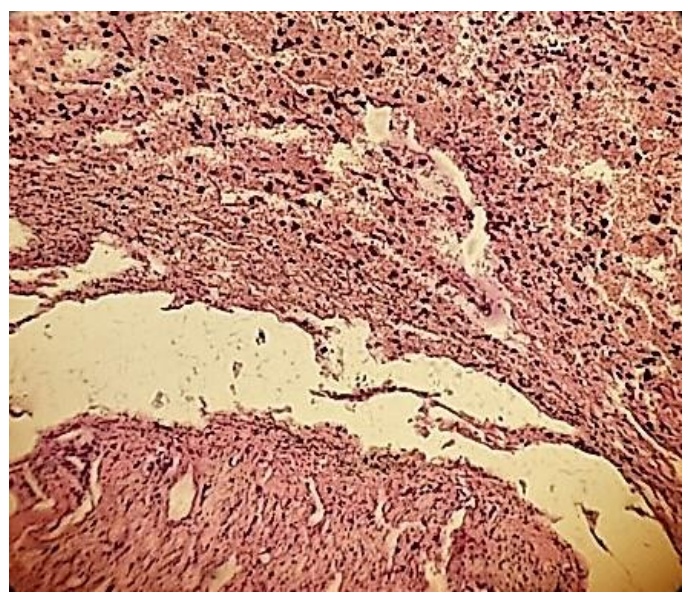

Fig. 3 Control group. $3^{\text {rd. }}$ day. Necrotic changes. Erythrocyte diapedesis.

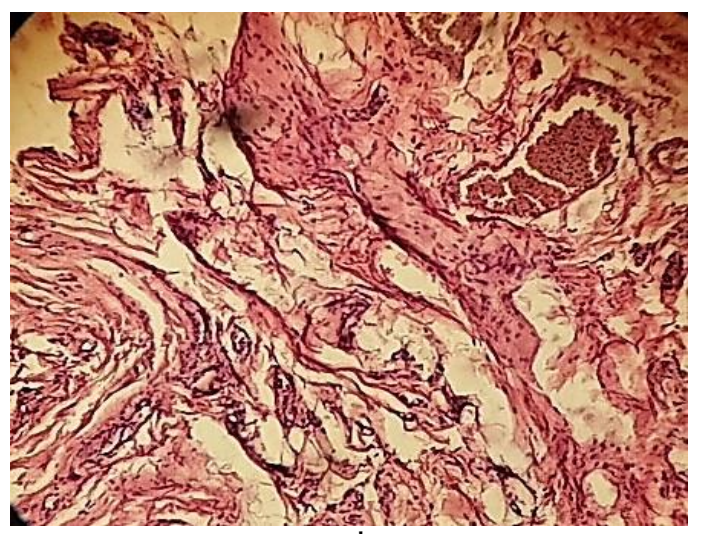

Fig. 5. Control group. $3^{\text {rd. }}$ day. Irregular chaotic changes in the connective tissue layer. 


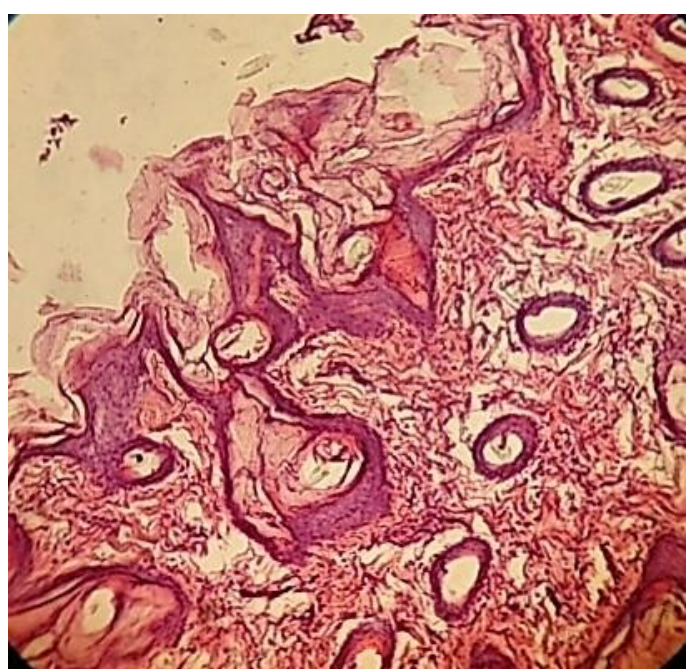

Fig. 6. Multilayer squamous epithelial parakeratosis and acanthosis. The hemostatic gel formed a layer on the squamous epithelium.

Vascular congestion (stasis). Experienced

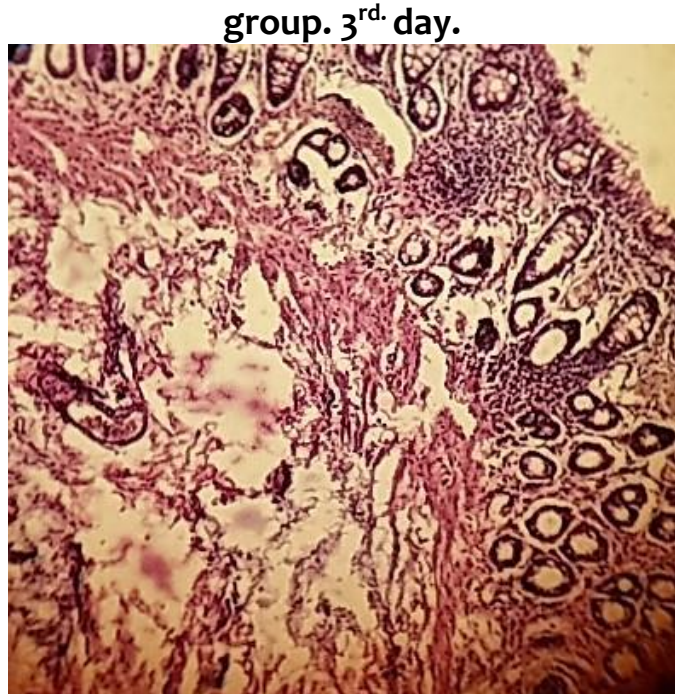

Fig. 8. Epithelial glandular layer of the rectum. Focal infiltration of histocytes and macrophages in different layers. Fibroblasts begin to form in the submucosa. Experienced group. $3^{\text {rd. }}$ day.

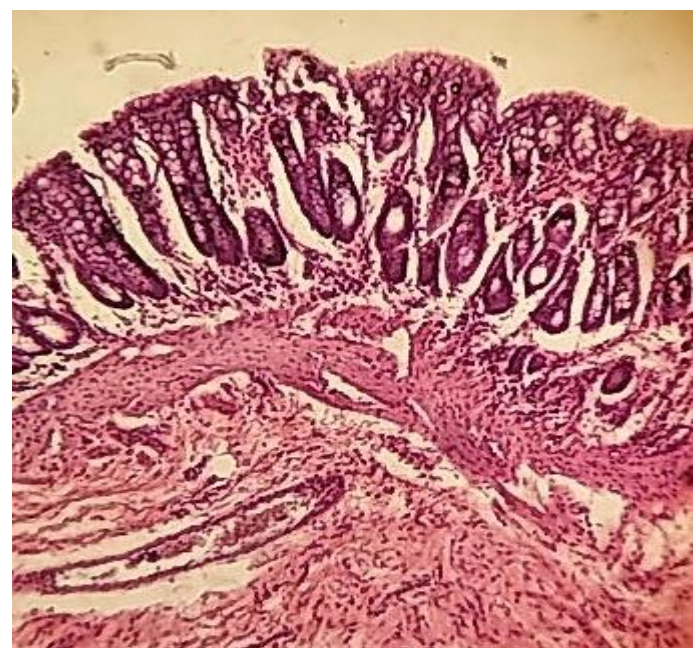

Rice. 7. Epithelial glandular layer of the rectum. Infiltration of histocytes and macrophages into different layers. Vascular dilation and congestion. Experienced group. $3^{\text {rd. }}$ day.

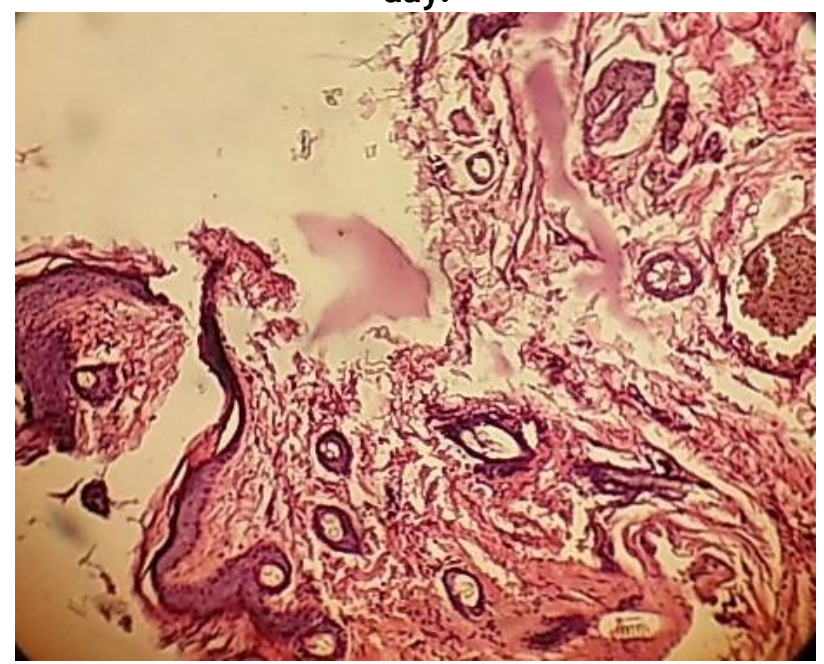

Fig. 9. Necrotic fibrinous layer, acanthosis, hyperkeratosis and parakeratosis on stratified squamous epithelium. Vascular congestion.

Paravasal edema. Control group. $5^{\text {th. }}$ day. 


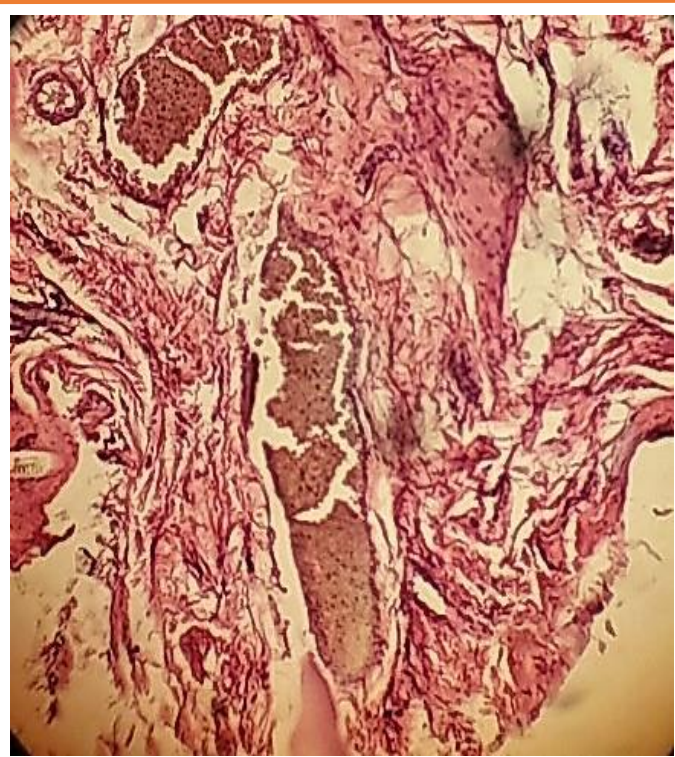

Fig. 10. Chaotic connective layer and fibroblasts, signs of mild congestion in the blood vessels and significant swelling around the blood vessels. Control group. $5^{\text {th. day. }}$

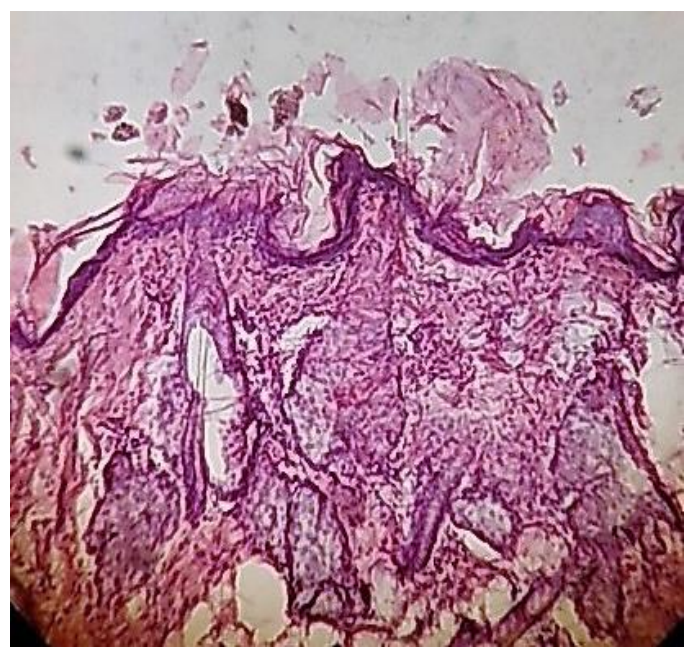

Fig. 12. Stratified squamous epithelium and a homogeneous hemostatic layer on top of it. Experienced group. $5^{\text {th. }}$ day.

On the 10th day of the experiment, the above difference became more obvious. In the control group, chaotic squamous epithelial cells and fibroblasts were formed. The fibrin-

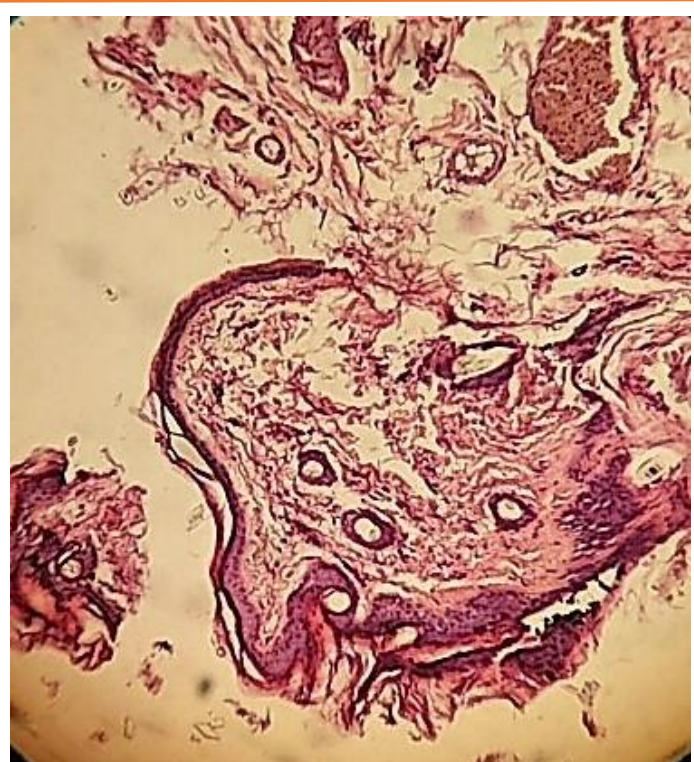

Fig. 11. Necrotic-fibrinous layer on stratified squamous epithelium, acanthosis, hyperkeratosis and parakeratosis. Expansion (dilatation) of blood vessels, filling and stasis (stasis). Paravasal edema. Control group. $5^{\text {th. }}$ day.

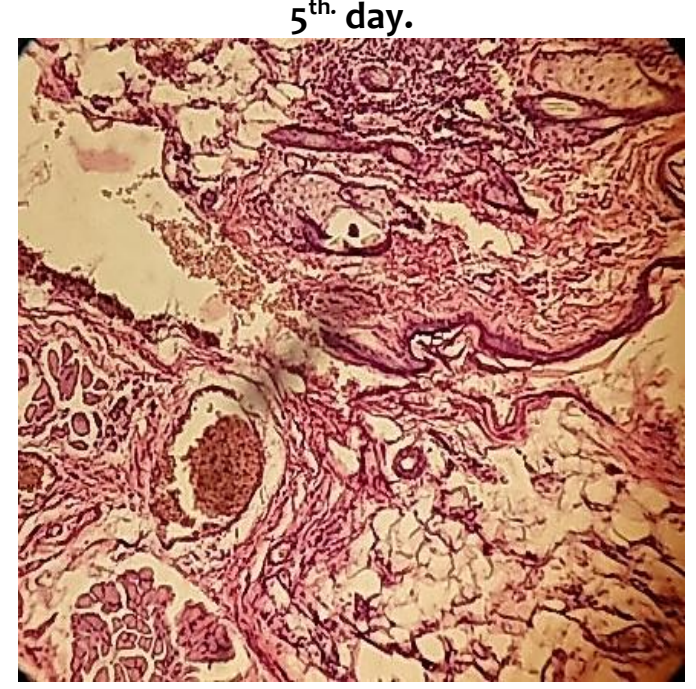

Fig. 13. The layer of hemostatic gel is preserved in the mucous membrane of the surgical incision site, as well as under it in the mucous membrane of the squamous epithelium, mainly in hyperkeratosis and acanthosis. Experienced group. $5^{\text {th. }}$ day.

necrotic layer is preserved. Focal infiltration of macrophages-lymphocytes was observed (Fig. 14 and 15). 


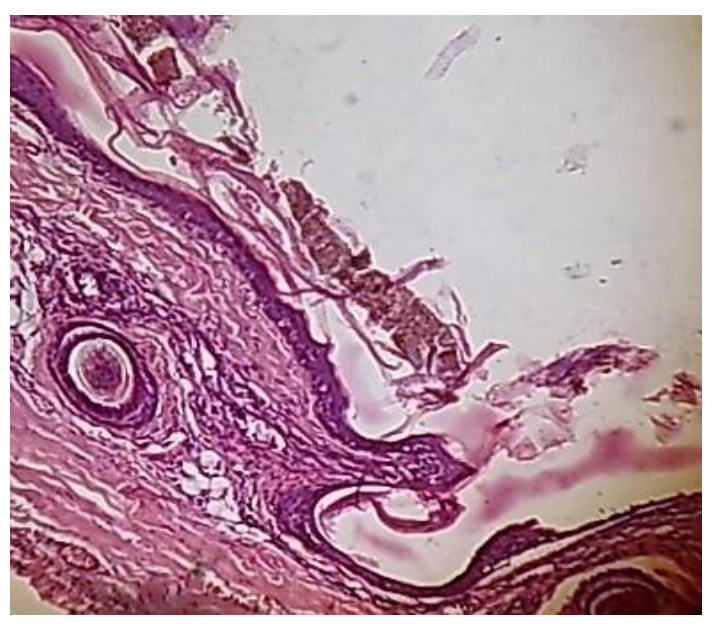

Fig. 14. A layer of necrotic fibrin and a layer of squamous epithelial cells underneath. Fibroblasts under the mucous membrane. Focal infiltration of macrophage-lymphocytes. Control group. $10^{\text {th. }}$. day.

The vessel wall is thickened, enlarged, filled. Diapedesis of significant extravascular hemorrhagic elements and tissue edema. Connective tissue has developed in the area of the surgical incision. In the experimental group, the intestinal layers began to change (Fig. 16). In the area of the surgical incision, the hemostatic layer is preserved; in this area, the growth of thin fibrous connective tissue is observed (Fig. 17). Differentiation and transformation of cells led to the regeneration of the epithelial layer and parakeratosis of the flat cell. Manifested by histocytic edema in the tissue layers (Fig. 18). The vessels are full. In short, the entire layer began to regenerate with a predominantly non-infectious effect (Fig. 19). Signs of complete remodeling were

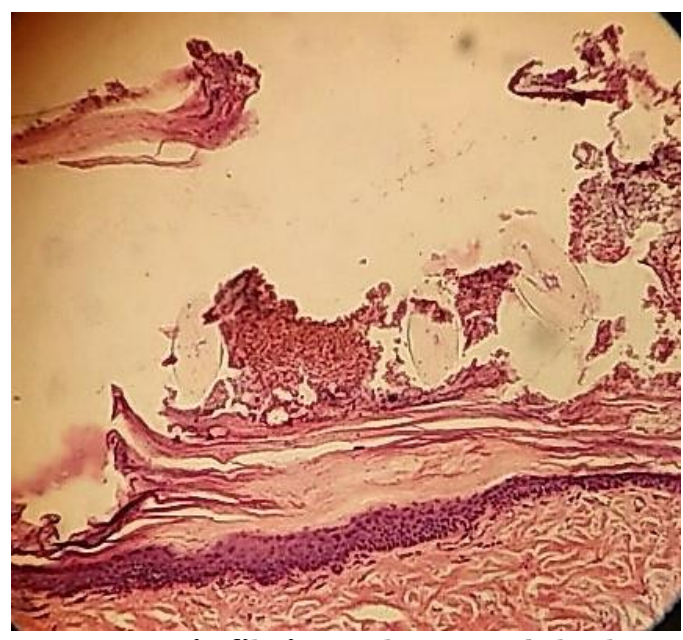

Fig. 15. Necrotic fibrinous layer and the layer of squamous epithelium cells underneath. Diapedesis of extravascular hemorrhagic elements and tissue edema. Control group. $10^{\text {th. }}$ day.

evident over a long period of time, such as 14 days. In the control group, the main regeneration of connective tissue in the tissue layers of the surgical incision area, focal lymphocytic infiltration occurred in different layers (Fig. 20-22), and in the experimental group, all layers were re-formed and all layers restored their histofunction. In some areas of the surgical incisions, remnants of the hemostatic gel layer are found. This is again manifested by significant vascular congestion (Fig. 23-25). 


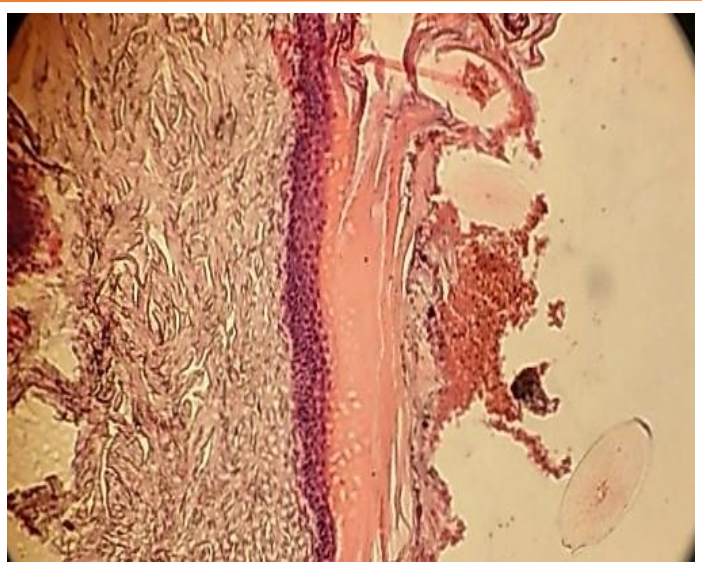

Fig. 16. Necrotic fibrin layer. Stratified squamous epithelium with hyperkeratosis. Diapedesis of extravascular hemorrhagic elements and tissue tumors. Control group. $10^{\text {th. }}$ days.

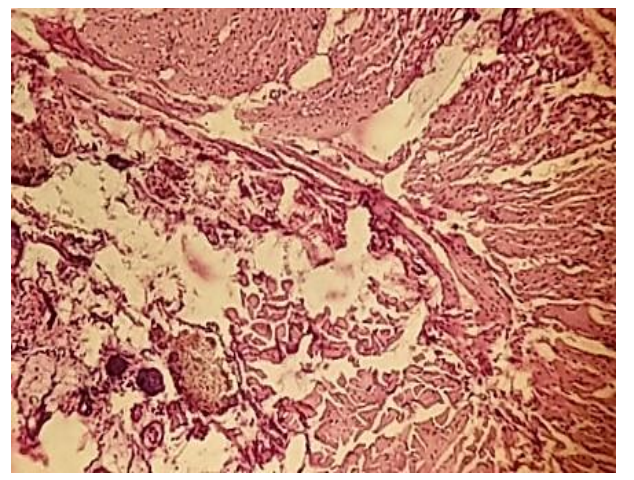

Fig. 18. The growth of thin fibrous connective tissue is observed. Histocytic edema in the tissue layers. Stable congestion in blood vessels and mild paravasal edema. Experienced group. $10^{\text {th. }}$ day.

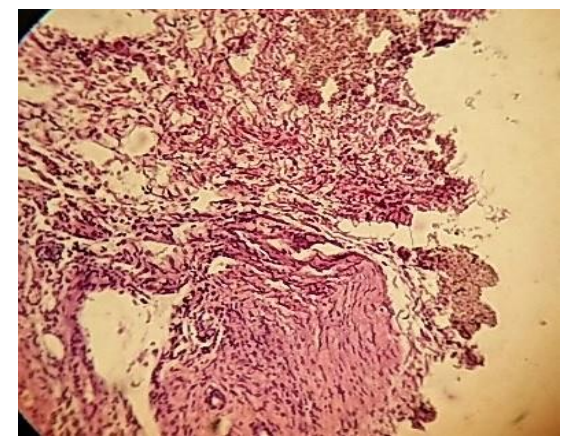

Fig. 20. Basic regeneration of the connective tissue layers of tissues in the area of the surgical incision. Focal lymphocytic infiltration in different layers. Control group. $14^{\text {th. }}$ day.

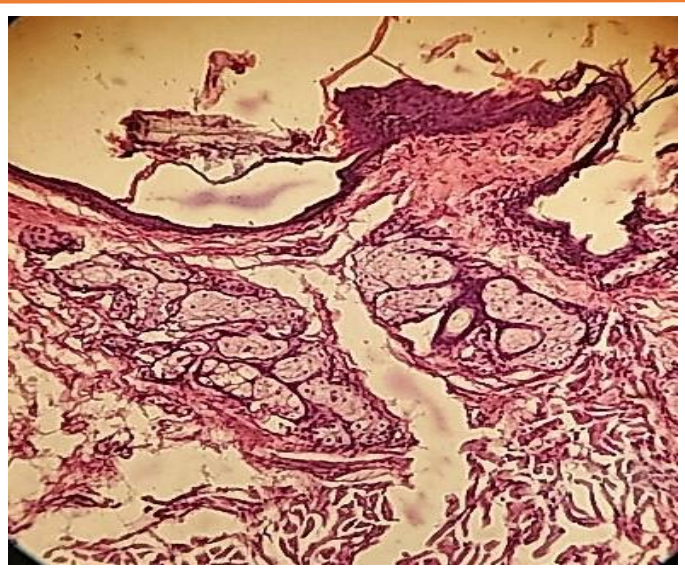

Fig. 17. As a result of differentiation and transformation of cells, the regeneration of the epithelial layer and parakeratosis of the flat cell occurs. The hemostatic gel layer was preserved, and thin fibrous connective tissue began to grow in this area. Experienced group. $10^{\text {th. }}$ day.

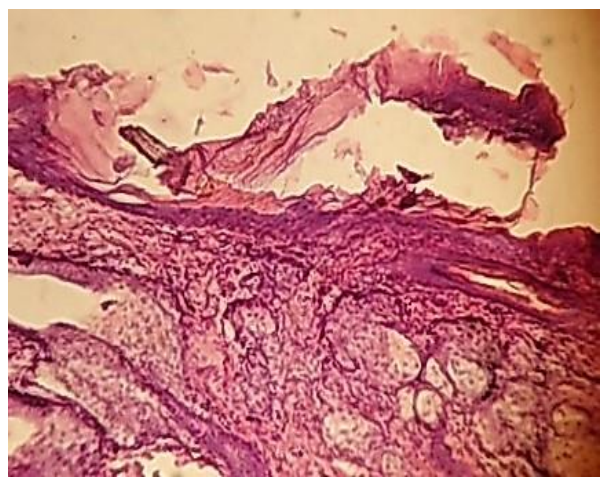

Fig. 19. Hemostatic layer in the area of the surgical incision. Restoration of epithelial layers and parakeratosis of a flat cell as a result of differentiation and transformation of cells. Experienced group. $10^{\text {th. }}$ days.

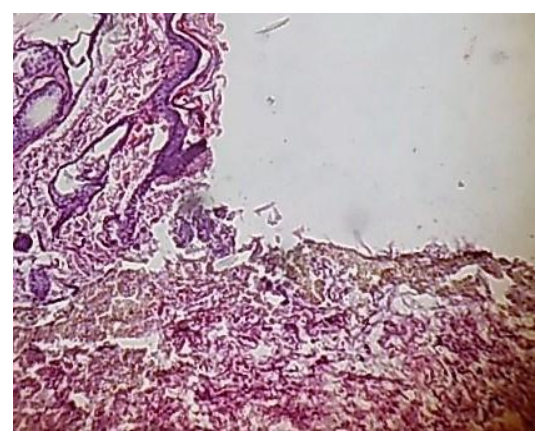

Fig. 21. Stratified squamous epithelium at the site of the surgical incision. Regeneration of connective tissue. Control group. $14^{\text {th. }}$ days. 


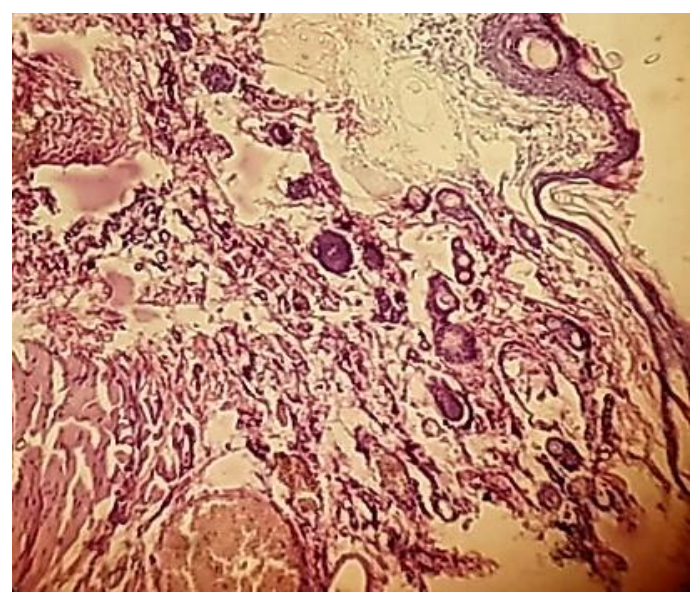

Fig. 22. Accumulated fibrin layer. Acanthosis with stratified squamous epithelium. Vascular congestion (stasis). Control group. $14^{\text {th. }}$ day.

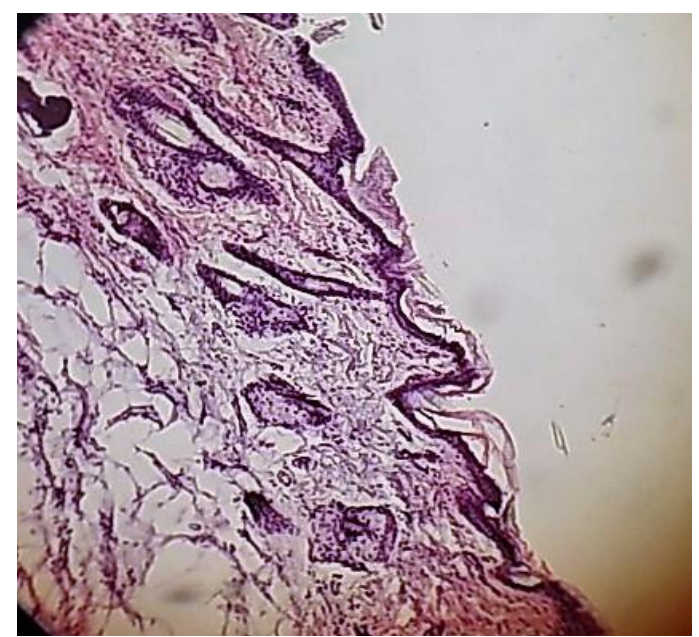

Fig. 24. A layer of hemostatic gel and stratified squamous epithelium underneath. Experienced group. $14^{\text {th. }}$ day.

A comparative analysis of the results of the above study showed that the hemostatic gel retains its hemostatic properties for a long time in the incisions formed in the experiment in the anal region. This, in turn, allows you to control and prevent bleeding during proctological operations. Of course, these possibilities, in turn, allow proctological operations with a significant reduction in

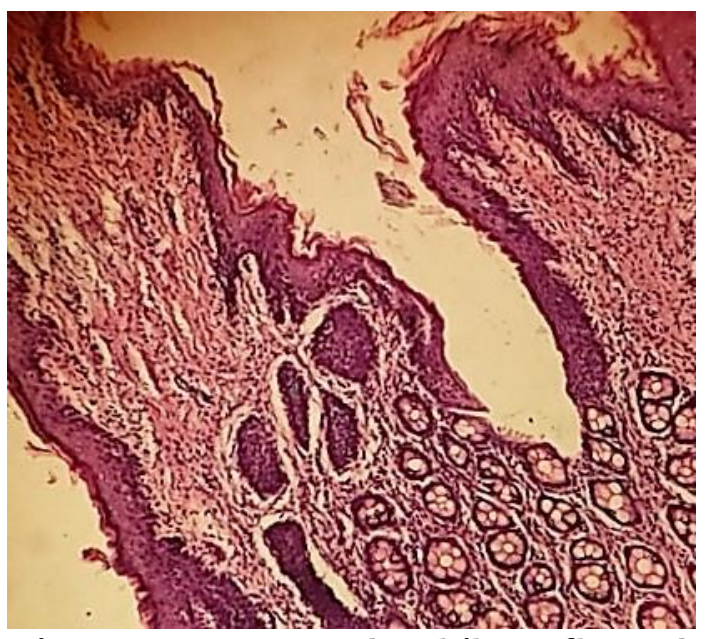

Fig. 23. Reconstructed multilayer flat and glandular epithelial layers. The remains of the hemostatic gel layer were found. Experienced group. $14^{\text {th. }}$ day.

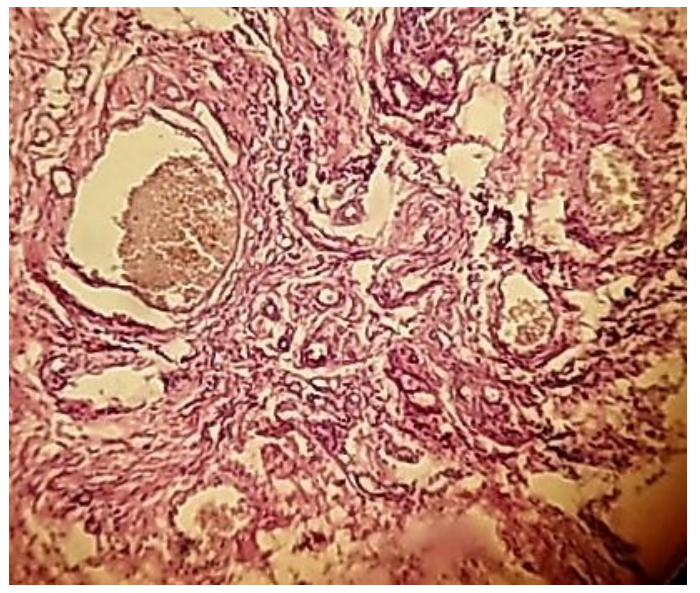

Fig. 25. Vascular congestion (stasis). Smooth fibroblasts. Experienced group. $14^{\text {th. }}$ day.

bleeding, especially in patients with hypocoagulation.

\section{CONCLUSION}

The use of the hemostatic coating "Heprocel" allows you to achieve a proliferative process of inflammation in the wound, while hemostasis by electrocoagulation promoted the 
development of necrotic-exudative inflammation processes. In turn, an important aspect is the presence of a layer of hemostatic gel in the mucous membrane in the area of the surgical incision, which provided persistent stagnation in the blood vessels. Also, in the experimental group, the growth of thin fibrous connective tissue was noted with restoration of the histofunction of the layers, while in the control, the main regeneration of connective tissue in the tissue layers was in the nature of focal lymphocytic infiltration.

Thus, it was proved that when using a hemostatic coating in the wound, the proliferative process of inflammation prevailed with the provision of persistent stagnation in the blood vessels, the successive growth of thin fibrous connective tissue with the restoration of the histofunction of the layers, while hemostasis by electrocoagulation promoted the development of necroticexudative processes with the regeneration of tissue layers. with elements of focal lymphocytic infiltration.

\section{REFERENCES}

1. Aigner F, Gruber $\mathrm{H}$, Conrad F, Eder J, Wedel $T$, Zelger $B$, Engelhardt $V$, Lametschwandtner A, Wienert $V$, Böhler $\mathrm{U}$, Margreiter R, Fritsch $\mathrm{H}$. Revised morphology and hemodynamics of the anorectal vascular plexus: impact on the course of hemorrhoidal disease. Int J Colorectal Dis. 2009 Jan;24(1):105-13. doi: 10.1007/s00384-008-0572-3.

2. Hollingshead JR, Phillips RK. Haemorrhoids: modern diagnosis and treatment. Postgrad Med J.
2016;92(1083):4-8.

doi:

10.1136/postgradmedj-2015-133328.

3. Lin HC, He QL, Shao WJ, Chen XL, Peng $\mathrm{H}$, Xie SK, Wang XX, Ren DL. Partial Stapled Hemorrhoidopexy Versus Circumferential Stapled Hemorrhoidopexy for Grade III to IV Prolapsing Hemorrhoids: A Randomized, Noninferiority Trial. Dis Colon Rectum. 2019 Feb;62(2):223-233. doi: 10.1097/DCR.0000000000001261.

4. Margetis N. Pathophysiology of internal hemorrhoids. Ann Gastroenterol. 2019 May-Jun;32(3):264272. doi: 10.20524/aog.2019.0355. Epub 2019 Jan 23. PMID: 31040623; PMCID: PMC6479658.

5. Salusso P, Testa V, Mochet S, Arezzo A, Allaix ME, Salzano A, Morino $M$, Mistrangelo $M$. Management of Hemorrhoidal Disease in Special Conditions: A Word of Caution. Rev Recent Clin Trials. 2021;16(1):22-31.

6. Sun Z, Migaly J. Review of Hemorrhoid Disease: Presentation and Management. Clin Colon Rectal Surg. 2016;29(1):22-9.

7. Pata F, Sgró A, Ferrara F, Vigorita V, Gallo G, Pellino G. Anatomy, Physiology and Pathophysiology of Haemorrhoids. Rev Recent Clin Trials. 2021;16(1):75-80. doi:10.2174/157488711566620040611515 o.

8. Tournu G, Abramowitz L, Couffignal C, Juguet F, Sénéjoux A, et al.; GREP study group; MG-PREVAPROCT study group. Correction to: Prevalence of anal symptoms in general practice: a prospective study. BMC Fam Pract. 2019;20(1):14. 
The American Journal of Applied sciences (ISSN - 2689-0992)

Published: September 24, 2021 | Pages: 5-15

9. Zagriadskiǐ E.A, Bogomazov A.M, Golovko EB. Conservative Treatment of

Hemorrhoids: Results of an Observational Multicenter Study. Adv Ther. 2018;35(11):1979-92. 